\title{
Análise da Performance de Streaming de Vídeos Adaptativos em Redes Veiculares V2I
}

\author{
Patrick Abrahão $^{1}$, Roger Immich ${ }^{2}$, Alfredo Goldman ${ }^{1}$ \\ ${ }^{1}$ Instituto de Matemática e Estatística (IME) \\ Universidade de São Paulo (USP) \\ ${ }^{2}$ Instituto Metropole Digital (IMD) \\ Universidade Federal do Rio Grande do Norte (UFRN) \\ patrick.menani@usp.br, \\ rogerdimd.ufrn.br, goldaime.usp.br
}

\begin{abstract}
The adoption of video-equipped cars, as well as connected and autonomous cars, has been gaining strength. The disponibility of services and applications in Vehicular Ad-Hoc Networks (VANETs) has been following the same trend. Thus, new kind of network is contemplated as a central component of the intelligent transportation systems, which provides support for a large variety of applications, including video service. These services permeate the network on a daily basis with video content. Seeking to better understand the video service behavior, this work assesses the adaptive video streaming performance over VANETS. The simulation results were assessed through QoS and QoE metrics and demonstrated that the MPEG-DASH is better at less dense scenarios, even when they have high mobility characteristics.
\end{abstract}

Resumo. O emprego de carros com equipamentos de vídeo, assim como veículos conectados e autônomos, tem experienciado um aumentando considerável. Os números de serviços e aplicações a disposição em Vehicular Ad-hoc Networks (VANETs) seguem a mesma tendência. Esse tipo de rede é contemplado com um componente central de sistemas de transporte inteligentes, que provê um suporte para uma grande variedade de aplicações, incluindo serviço de vídeo. Esses serviços permeiam a rede com conteúdo de vídeo diariamente. Com o objetivo de entender melhor o comportamento destes serviços, este trabalho realiza uma análise da performance de streaming de vídeos adaptativos em VANETs. Resultado das simulações comprovam, através de métricas de QoS e QoE, que o MPEG-DASH apresenta mais vantagens em cenários menos densos, ainda que estes apresentem características de movimentação acentuada.

\section{Introdução}

Nos últimos anos houve um grande aumento na utilização de serviços de vídeo. Estas aplicações estão presentes em redes sociais, vídeo sob demanda e até em jogos interativos. Para aumentar a demanda, cada vez são produzidos melhores dispositivos móveis [Adobe Digital Index 2018], colocando um grande poder de processamento nas mãos dos usuários. Isto permite o fácil acesso à produção, consumo e disponibilização de conteúdos multimídia. Todas as facilidades levam a um considerável aumento no tráfego de rede. Somente para citar um exemplo, de acordo com a Cisco, mais de $70 \%$ da população mundial terá acesso à conexão móvel até 2023. Adicionalmente, é esperado que a transmissão de vídeo represente mais de $82 \%$ do trafego total da Internet [Cisco 2018].

A crescente demanda e o avanço tecnológico em serviços de Internet e aparelhos móveis geraram uma necessidade da adaptação do modelo tradicional de oferecimento 
dos conteúdos de mídias digitais. Com o foco na melhoria da qualidade de experiência do usuário, foi desenvolvida a técnica de Dynamic Adaptive Streaming over HTTP (MPEGDASH), que ajusta automaticamente a qualidade do vídeo em função das condições da rede. Atualmente ela é utilizada por diversos provedores de serviço de vídeo online como YouTube, Netflix e Facebook.

Por outro lado, o avanço tecnológico recente em dispositivos portáteis possibilitou a adição de componentes com uma capacidade de processamento e aquisição de informação nos veículos c. Esse ambiente, conhecido como Vehicular Ad-hoc Networks (VANETs) é composto por uma estrutura capaz de fornecer dados para veículos que trafegam em uma determinada área [Immich et al. 2015]. De uma forma geral, estas redes podem ser categorizadas como vehicle to vehicle (V2V), onde a comunicação é realizada diretamente entre os nodos, vehicle to infrastructure (V2I), onde a comunicação é realizada através de uma infraestrutura existente, ou híbrida, onde existe uma combinação de infraestrutura e comunicação direta entre os veículos [Akabane and et al. 2018a]. Redes veiculares têm apresentado atualmente vantagens como controle eficiente de tráfego, maior segurança e possibilidade de desenvolvimento de novos recursos [Immich et al. 2018].

Levando-se em consideração o grande crescimento na demanda pela transmissão de vídeo, bem como o desenvolvimento e aprimoramento das redes veiculares, este trabalho tem como objetivo apresentar uma análise da performance de streaming de vídeos adaptativos em redes veiculares V2I. Esta análise de performance será realizada através do simulador de rede Objective Modular Network Testbed (OMNet++). Serão analisados parâmetros relacionados a rede, através de métricas de Quality of Service (QoS) e também parâmetros relacionados com a percepção do usuário final, através de métricas de Quality of Experience (QoE).

O restante deste trabalho está organizado da seguinte forma. Na Seção 2 são apresentados os trabalhos relacionados. A descrição dos cenários, detalhes de implementação e avaliação dos resultados são discutidos na Seção 3. A conclusão e trabalhos futuros são apresentados na Seção 4.

\section{Trabalhos Relacionados}

Diversos estudos vêm sendo desenvolvidos buscando soluções para uma transmissão eficiente de vídeos em VANETs. Em [Immich et al. 2014] o autor explica os conceitos chaves para a realização e avaliação de uma transmissão de vídeo. Em relação as análises de qualidade, o autor propõe e aplica métricas subjetivas de QoE e métricas objetivas de QoS. O autor também propõe modos de otimizar a transmissão do vídeo nesses cenários.

Um framework é proposto em [Rosário et al. 2013] para realizar simulações de vídeo. Este possui embarcada as funcionalidades de transmissão e análise de mídia de vídeo, com a integração das funcionalidades do Evalvid. Mas, neste trabalho os autores não abordam o uso desses simuladores em ambientes de VANETs e não citam a possibilidade de integração com simuladores como Veins e SUMO para a implementação deste tipo de rede.

Outros trabalhos, como [Akabane and et al. 2018b, Ferronato and Trentin 2015, Noori 2012], fazem uso da combinação do OMNeT++ com outros de seus frameworks como o Veins e o SUMO, para simularem tráfego urbano de forma realista. Nestes trabalhos os autores analisam de forma objetiva a capacidade de se realizar uma simulação de VANETs. Porém, eles não analisam o aspecto da integração com alguns outros tipos de simuladores como o INET para as simulações mais aproximadas de redes sem fio. 


\section{Definição dos Cenários e Análise da Performance dos Vídeos Adaptativos}

Esta seção descreve os cenários simulados a partir de mapas reais, acompanhado da avaliação da performance dos vídeos adaptativos. Todas as comunicações entre os veículos foram realizadas através de V2I, ou seja, os veículos se comunicam entre si através da infraestrutura presente. A Figura 1 apresenta a arquitetura desenvolvida para a realização dos experimentos. Um recorte do mapa da Cidade Universitária da USP foi obtido no OpenStreetMap e carregado no Simulation of Urban Mobility (SUMO). Através da importação de um ambiente real, foi possível definir rotas verídicas para os veículos, bem como programar todos os parâmetros de mobilidade veicular, entre eles velocidades mínimas e máximas, aceleração, desaceleração e tempos de pausa.

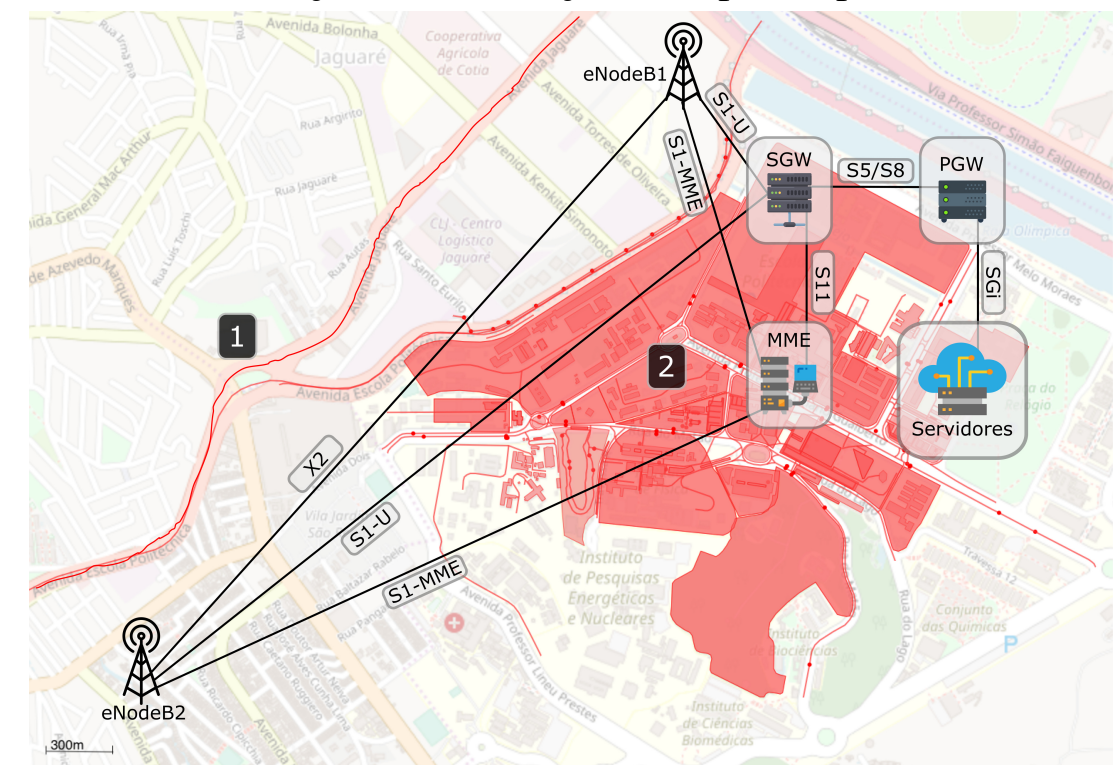

Figura 1. Arquitetura baseada no mapa real da Cidade Universitária da USP

Adicionalmente, o simulador $\mathrm{OMNeT}++$ foi adotado para a criação de estrutura Long Term Evolution (LTE) e seus devidos canais de comunicação. O ambiente simulado baseado no núcleo padrão LTE, conhecido como System Architecture Evolution (SAE) e seu subsistema Evolved Packet Core (EPC), conforme especificado pelo 3 GPP [Olsson et al. 2009]. Nos experimentos, temos duas estações rádio base (eNodeB1 e eNodeB2). As estações estão conectadas à Mobility Management Entity (MME) através da interface S1-MME, que é responsável pelo controle da rede de acesso, autenticação, cifragem, interligação com redes legadas e mobilidade. O Serving Gateway (SGW) é responsável por realizar o roteamento de pacotes para os usuários, agindo também como âncora de mobilidade durante handovers. Este elemento é interligado com as estações de rádio base através da interface $\mathrm{S} 1-\mathrm{U}$, já a interface X2 é utilizada para interligar dois eNodeBs. Outro elemento desta arquitetura é o PDN Gateway (PGW). Ele aprovisiona a conectividade entre os usuários móveis e as redes de dados externas. Desta forma, ele pode ser considerado o nó de entrada e saída do tráfego de dados, podendo implementar políticas de controle, tarifação, filtragem de pacotes, entre outros. O SGW utiliza as interfaces S5/S8 para se comunicar com o PGW, que por sua vez, utiliza a interface SGi para se conectar aos servidores externos. No cenário apresentado, os servidores armazenam as aplicações MPEG-DASH.

\subsection{Cenários Experimentais}

O primeiro cenário simula a interseção de duas autoestradas. Próximo a esta intersecção, existem duas estações base LTE que permitem a comunicação entre os veículos e as redes 
locais, incluindo servidores de conteúdo. Figura 1 região [1] exibe este cenário. Nestas condições, os carros se movimentam em velocidades relativamente altas, permanecendo entre 90 e $110 \mathrm{~km} / \mathrm{h}$. O segundo ambiente consiste de um cenário de simulação de mobilidade urbana na cidade universitária da USP em São Paulo. Este cenário possui configurações de rede similares ao anterior, porém, alternando as ruas e variando sua velocidade de 20 a $50 \mathrm{~km} / \mathrm{h}$. Figura 1 região [2] exibe este cenário.

Para as avaliações experimentais, e deixar a simulação mais realista, foram executadas simulações com um número total de trinta a setenta carros simultaneamente. Dentre estes, dez carros possuem a aplicação de vídeo adaptativo, gerando lotes de experiências para cada cenário veicular e de transmissão de vídeo. No geral, os carros que não possuíam a aplicação em análise estavam rodando aplicações genéricas ou apenas conectados a rede sem trocar informações com os servidores.

Cada simulação dos experimentos utiliza uma janela de sessenta segundos para a avaliação do envio de dois vídeos pela aplicação. Um vídeo de treze segundos mais dinâmico que representa uma rua com diversas pessoas se movimentando, nomeado BusyStreet. O outro vídeo, de dez segundos, com alguns carros parando em um semáforo de trânsito, este um pouco menos dinâmico e com menos elementos se movimentando, nomeado CarsStoping. Ambos os vídeos estão disponíveis na plataforma do YouTube [Bill 2018].

Para a facilitar da análise dos dados, o MPEG-DASH foi configurado com um intervalo de um segundo para cada pacote e sua variação do vídeo. Isto significa que podemos ter variação de qualidade do vídeo a cada um segundo de simulação. Adicionalmente, a partir da primeira requisição da aplicação de streaming e a cada segundo de simulação, deveríamos ter um segundo de reprodução do vídeo.

\subsection{Análise dos Resultados}

Com o objetivo de realizar uma análise holística dos resultados, estes foram divididos em duas etapas, uma baseada em QoS e a outra em QoE. A primeira é sobre a análise dos resultados levando-se em consideração parâmetros exclusivamente de rede, comumente avaliados através de métricas de QoS. As métricas adotadas foram a perda de pacotes e o atraso médio na entrega. A primeira delas, perda de pacotes, consiste em avaliar quantos pacotes a aplicação requisitou e quantos ela recebeu do servidor. A segunda métrica de avaliação, atraso médio de entrega dos pacotes na rede pela aplicação, representa a medida do tempo de atraso entre a aplicação requisitar um pacote de vídeo e receber ele para exibição. Utilizando essas duas métricas é possível avaliar a performance objetiva da aplicação em relação a rede e o usuário. Para capturar detalhes de QoE, a segunda parte faz uma avaliação do ponto de vista do usuário, buscando entender como este percebe a qualidade do vídeo que está sendo recebido.

Para a análise de QoE da aplicação foram adotadas três métricas, que são a qualidade média, o atraso de reprodução e a ocupação do buffer. A primeira delas, qualidade média do vídeo (bitrate), é medida em todos os nós que contêm a aplicação. Assim é possível avaliar se o vídeo foi reproduzido em uma qualidade alta, média ou baixa, sendo essas respectivamente $720 \mathrm{p}$ (1500 Kbps), 540p (800 Kbps) e 320p (400 Kbps). Portanto, podemos avaliar a experiência do usuário quanto ao vídeo reproduzido, pois é possível supor que vídeos com uma qualidade maior agradam mais o usuário do que os de qualidade inferior.

A segunda métrica, atraso de reprodução dos segmentos do vídeo, avalia o tempo que cada segmento do vídeo deve ser reproduzido em relação ao anterior. Se o atraso de reprodução de cada segmento for maior do que alguns milissegundos, o usuário pode ter sua experiência comprometida devido a travamentos durante a reprodução. A terceira, e 
última métrica, é a ocupação do buffer. Ela tem como objetivo medir a quantidade de recarregamentos que aplicação realiza durante a exibição do vídeo. Isto é importante, pois em situações de muitos recarregamentos o usuário pode experienciar travamentos da aplicação e diversas mudanças de qualidade. Os resultados foram obtidos através de trinta simulações para cada combinação de cenário e vídeo.

\subsubsection{Avaliação dos Parâmetros de Rede (QoS)}

As Tabelas 1 e 2 apresentam o atraso médio e a perda de pacotes nos cenários de autoestrada e mobilidade urbana. Na Tabela 1 é possível perceber que, em média, o atraso ficou abaixo de 0.3 segundos, com um desvio padrão também, de aproximadamente 0.3 segundos. Isto demonstra que existe uma grande variação na entrega dos pacotes, porém, nos permite inferir que os mesmos tiveram um atraso geral abaixo de 1 segundo (média + desvio padrão). Portanto, é possível afirmar que, em geral, os pacotes requisitados chegam em menos de 1 segundo da requisição pela aplicação. Adicionalmente, a perda média ficou abaixo de $1 \%$ dos pacotes, com um desvio padrão menor que $0.02 \%$. Portanto, a confiabilidade da aplicação na rede é mantida. Desta forma, podemos assumir que a aplicação teve um bom desempenho na rede em relação a garantia de entrega de pacotes nas diversas aplicações de streaming.

Tabela 1. QoS Autoestrada

\begin{tabular}{c|c|c}
\hline Parâmetros & $\begin{array}{c}\text { Atraso entrega } \\
\text { de pacotes }\end{array}$ & $\begin{array}{c}\text { Perda de } \\
\text { pacotes }\end{array}$ \\
\hline \hline Média & $0.273 \mathrm{~s}$ & $0.971 \%$ \\
Desvio Padrão & $0.314 \mathrm{~s}$ & $0.026 \%$ \\
\hline
\end{tabular}

Tabela 2. QoS Mobilidade Urbana

\begin{tabular}{c|c|c}
\hline Parâmetros & $\begin{array}{c}\text { Atraso entrega } \\
\text { de pacotes }\end{array}$ & $\begin{array}{c}\text { Perda de } \\
\text { pacotes }\end{array}$ \\
\hline \hline Média & $2.728 \mathrm{~s}$ & $2.962 \%$ \\
Desvio Padrão & $0.660 \mathrm{~s}$ & $0.596 \%$ \\
\hline
\end{tabular}

Na Tabela 2, como pode ser observado, o atraso médio entre os pacotes é de um pouco mais que 2.7 segundos, com um desvio padrão superior a meio segundo. Estes valores podem ser considerados relativamente altos, se levarmos em consideração que cada segmento de vídeo possuí apenas 1 segundo. Isto representa mais do que o dobro em relação ao tempo de execução de um segmento e se for somado o desvio padrão, pode chegar a mais de três vezes. Portanto, podemos assumir que o atraso na rede não é adequado no cenário de mobilidade urbana. É importante ressaltar que este atraso pode ser aliviado, ou até mesmo desconsiderado, com a utilização de um buffer maior. Por outro lado, isto pode levar a um tempo maior de carregamento inicial, que também gera insatisfação dos usuários. A perda de pacotes ficou em quase $3 \%$, com um desvio padrão de um pouco mais de $0.5 \%$. Esta taxa pode ser considerada alta para redes cabeadas, porém, em uma rede com grande mobilidade de usuários representa um valor baixo.

\subsubsection{Avaliação dos Parâmetros de Qualidade de Experiência (QoE)}

Conforme mencionado anteriormente, para avaliar a QoE serão utilizadas três métricas, que são a ocupação do buffer, a qualidade do vídeo (bitrate) e o atraso na reprodução. As Figuras 2 e 3 apresentam a análise de QoE em termos de ocupação do buffer nos cenários de autoestradas e mobilidade urbana, respectivamente. Esta avaliação é importante porque um buffer com uma boa ocupação consegue esconder o atraso e a latência dos pacotes, garantindo assim, uma melhor qualidade de experiência para os usuários finais. O buffer também pode ajudar a prevenir pausas para carregamento e uma qualidade aceitável de imagem mesmo quando acontecem flutuações na largura de banda e erros esporádicos na rede. Estes gráficos não apresentam o desvio padrão pois os valores encontrados foram negligenciáveis. É possível visualizar que, em ambos os cenários, o comportamento de 
carregamento e consumo do buffer é muito próximo. Isto já era esperado na avaliação, pois nos dois cenários a comunicação dos nodos é realizada através da infraestrutura, o que permite uma comunicação mais consistente em função da baixa distância das antenas.

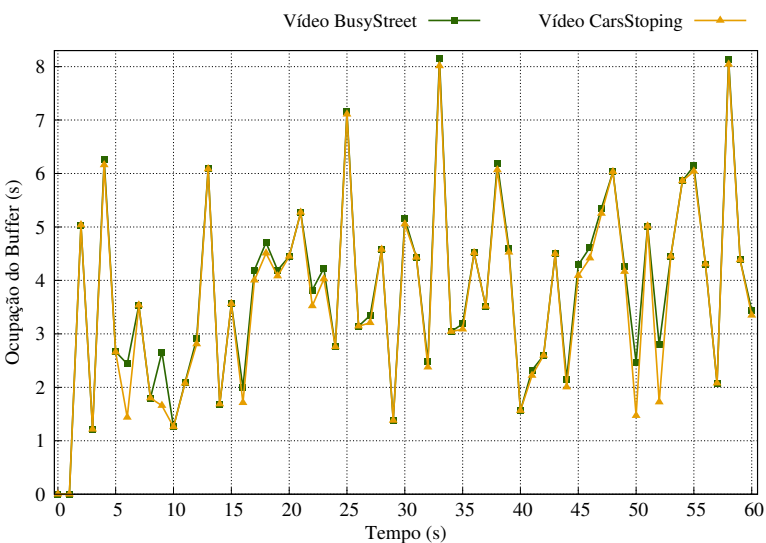

Figura 2. Ocupação do buffer cenário autoestradas

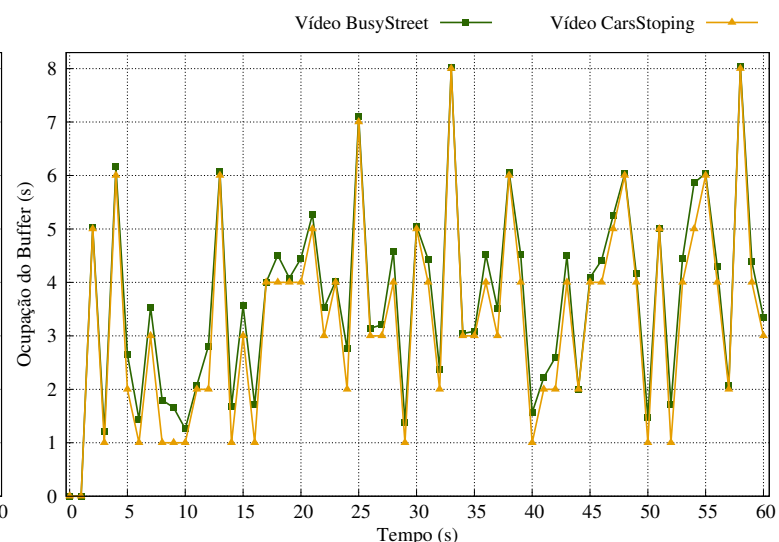

Figura 3. Ocupação do buffer cenário mobilidade urbana

A Tabela 3 apresenta as médias e desvios padrões da ocupação do buffer nos dois cenários dos experimentos. No cenário da autoestrada, é possível observar que a média da ocupação se mantém perto de 4.5 segundos e o desvio padrão fica em torno de 2.7 segundos. Portanto, a aplicação no geral sempre possui diversos segmentos para o MPEGDASH reproduzir, os eventos de recarregamento acontecem, porém não devem interferir na execução da aplicação. No cenário de mobilidade urbana, a média ficou mais próxima de 3.6 segundos, com um desvio padrão entre 2.3 e 2.45 segundos. De uma maneira geral, podemos dizer que este cenário ficou com 1 segundo a menos de buffer. Isto significa que haverá uma maior chance de o usuário perceber um travamento caso a rede não consiga suprir a entrega de todos os pacotes em tempo hábil de reprodução do vídeo. Isto demonstra que o cenário de mobilidade urbana apresenta condições mais restritivas para $o$ funcionamento do MPEG-DASH.

Tabela 3. Média e desvio padrão da ocupação do buffer

\begin{tabular}{c|c|c}
\hline Parâmetros & Autoestrada & Mobilidade urbana \\
\hline \hline \multicolumn{3}{c}{ Vídeo BusyStreet } \\
\hline Média & $4.495 \mathrm{~s}$ & $3.599 \mathrm{~s}$ \\
Desvio padrão & $2.752 \mathrm{~s}$ & $2.300 \mathrm{~s}$ \\
\hline \multicolumn{3}{c}{ Vídeo CarsStoping } \\
\hline Média & $4.685 \mathrm{~s}$ & $3.792 \mathrm{~s}$ \\
Desvio padrão & $2.643 \mathrm{~s}$ & $2.455 \mathrm{~s}$ \\
\hline
\end{tabular}

As Figuras 4 e 5 apresentam a variação da qualidade do vídeo nos experimentos. É possível notar que durante a transmissão do vídeo CarsStoping não ocorreu nenhuma alteração do bitrate em nenhum dos cenários testados. Estes gráficos também não apresentam o desvio padrão pois, da mesma fora que nos gráficos da ocupação do buffer, os valores encontrados foram negligenciáveis. Ou seja, o MPEG-DASH identificou desde o início precisamente a melhor resolução possível levando em consideração as condições da rede. Por outro lado, durante a transmissão do vídeo BusyStreet houve algumas tentativas para aumentar o bitrate de transmissão em ambos os cenários. Porém, nenhuma delas com sucesso, pois logo na sequência processou-se o retorno a qualidade anterior (400 Kbps). É possível notar também que o cenário de mobilidade urbana apresenta maior instabilidade (Figura 5), havendo mais tentativas de troca de qualidade.

A Tabela 4 apresenta a média e desvio padrão da qualidade de transferência dos 


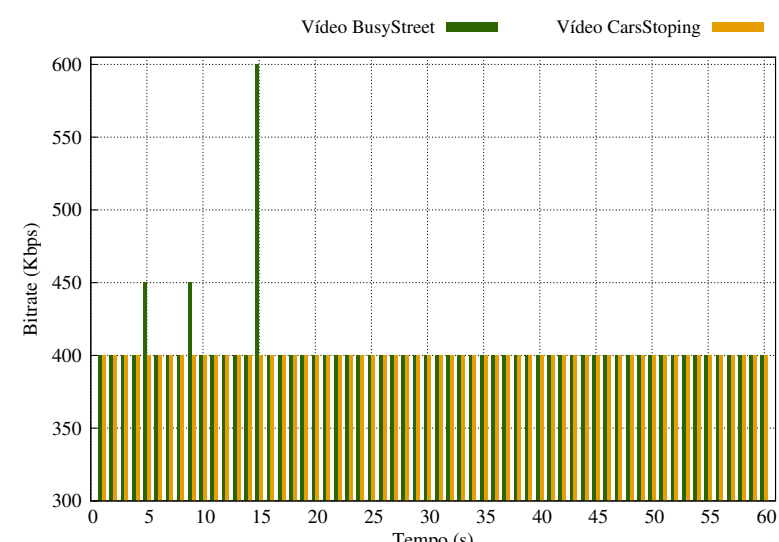

Figura 4. Qualidade média (bitrate) - cenário autoestradas

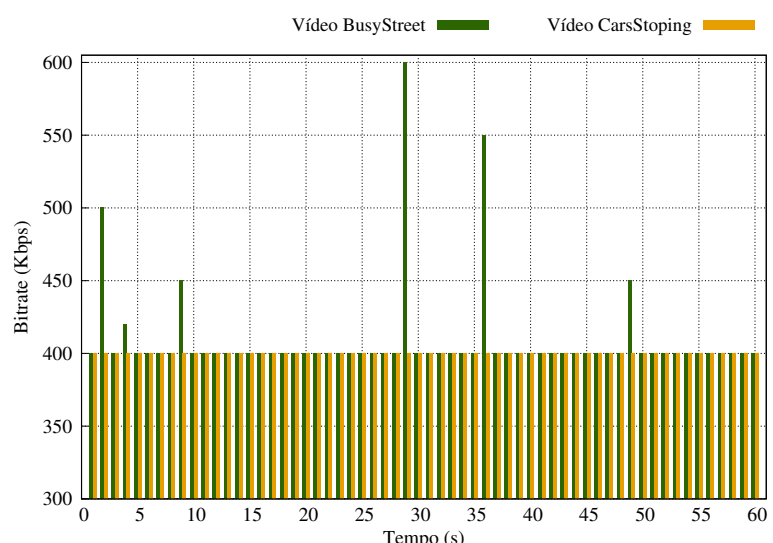

Figura 5. Qualidade média (bitrate) - cenário mobilidade urbana

vídeos em cada um dos cenários. No geral, podemos notar que a média da qualidade dos segmentos de vídeo é em torno dos $400 \mathrm{Kbps}$. Desta forma, é possível concluir que a rede utilizada não tem qualidade suficiente, de acordo com os critérios do MPEG-DASH, para transportar quadros de vídeos com maior bitrate. Estes mantem então, uma qualidade mais baixa afim de valorizar uma reprodução mais fluida e contínua do vídeo, ao invés de uma alta qualidade final. Como pode ser visto pela quantidade de trocas de qualidade, $o$ cenário de mobilidade urbana impõe maior complexidade para o MPEG-DASH escolher a melhor resolução. Esta situação pode muito bem ser visualizada desvios padrões para o vídeo BusyStreet, onde o maior desvio é alcançado justamente no cenário de mobilidade urbana.

\begin{tabular}{|c|c|c|}
\hline Parâmetros & Autoestrada & Mobilidade urbana \\
\hline \multicolumn{3}{|c|}{ Vídeo BusyStreet } \\
\hline Média & $405.0 \mathrm{Kbps}$ & $409.5 \mathrm{Kbps}$ \\
\hline Desvio padrão & $27.1 \mathrm{Kbps}$ & $35.1 \mathrm{Kbps}$ \\
\hline \multicolumn{3}{|c|}{ Vídeo CarsStoping } \\
\hline Média & $400 \mathrm{Kbps}$ & $400 \mathrm{Kbps}$ \\
\hline Desvio padrão & $0.0 \mathrm{Kbps}$ & $0.0 \mathrm{Kbps}$ \\
\hline
\end{tabular}

A última métrica de QoE avaliada foi o atraso na reprodução do conteúdo. A Tabela 5 exibe os resultados para os dois cenários estudados. O atraso na reprodução pode ser considerado algo semelhante ao atraso na entrega dos pacotes, que também pode ter o seu efeito atenuado com a utilização dos buffers. No cenário de autoestrada, tem um atraso médio inferior a 0.1 segundos. Isto significa que dificilmente os usuários sofrerão de travamentos perceptíveis, pois os mesmos serão insignificantes. Se levarmos em conta o desvio padrão, que ficou em 0.24 segundos, é possível perceber uma grande variação nos resultados. Desta forma, podemos inferir que em alguns casos a variação foi maior e o usuário poderia experienciar alguns travamentos ligeiros entre o final de um segmento e o início do próximo. No cenário de mobilidade urbana, podemos perceber uma média consideravelmente maior, ficando acima dos 1.3 segundos. Da mesma forma que no cenário anterior, o desvio padrão também ficou alto, em mais de 1.8 segundos. Aqui novamente, temos uma coleção de resultados que apresentam uma grande variação. Ainda assim, é possível concluir que os usuários deste cenário podem experimentar travamentos longos o suficiente para que afete sua qualidade de experiência.

\section{Conclusões}

A transmissão de vídeos com qualidade para os usuários finais é cada vez mais valorizada, pois isto é importante identificar e estudar mecanismos que possibilitem que ela 
Tabela 5. Atraso na reprodução dos vídeos

\begin{tabular}{c|c|c}
\hline Parâmetros & Autoestrada & Mobilidade urbana \\
\hline \hline Média & $0.0912 \mathrm{~s}$ & $1.339 \mathrm{~s}$ \\
Desvio padrão & $0.2400 \mathrm{~s}$ & $1.898 \mathrm{~s}$ \\
\hline
\end{tabular}

seja realizada de uma maneira mais eficiente. Considerando as métricas analisadas, podemos avaliar que o algoritmo do MPEG-DASH se comporta melhor em cenários menos densos, mesmo que estes apresentem um dinamismo de movimento maior, como pode ser observado no cenário das autoestradas. Porém, pode ter seu desempenho prejudicado quando tratamos de ambientes mais densos e com um dinamismo maior de nós na rede, como o cenário da mobilidade urbana da cidade universitária da USP. Esses dados nos levam a crer que a técnica é eficiente em cenários como o das rodovias. Estes são grande parte dos cenários do futuro, que deverão abranger cada vezes mais grandes viagens e carros autônomos, podendo ser muito útil a reprodução de mídias digitais durante os trajetos, tanto para entretenimento como para acesso a informações. Contudo, em casos de mobilidade urbana, como previsto em grandes cidades, a técnica deve ser adaptada ou sofrer algum tipo de ajuste fino para obter um melhor desempenho. Desta forma, pode ser possível obter o máximo das suas técnicas de adaptação do bitrate e seu carregamento eficiente do buffer. Temos então que o protocolo MPEG-DASH pode ser uma boa opção para transmissões em redes como as VANETs no futuro. Adicionalmente, como trabalhos futuros, se forem consideras adaptações inteligentes, que tirem proveito dos cenários mais densos e com o carregamento prévios de informações, será possível alcançar um desempenho ainda maior durante a reprodução de vídeos.

Agradecimentos - Este trabalho foi parcialmente financiado pela bolsa 2018/02204-6 da Fundação de Amparo à Pesquisa do Estado de São Paulo (FAPESP) e pela Coordenação de Aperfeiçoamento de Pessoal de Nível Superior - Brasil (CAPES) - Código de Financiamento 001. Este trabalho faz parte do projeto INCT denominado Internet do Futuro para Cidades Inteligentes (CNPq 465446/2014-0, CAPES 88887.136422/2017-00 e FAPESP 2014/50937-1).

\section{Referências}

Adobe Digital Index (2018). A look at the 2018 adobe mobile maturity survey. Technical report, Adobe.

Akabane, A. T. and et al. (2018a). Distributed egocentric betweenness measure as a vehicle selection mechanism in vanets: A performance evaluation study. Sensors, 18(8):2731.

Akabane, A. T. and et al. (2018b). iMOB: An intelligent urban mobility management system based on vehicular social networks. In IEEE Vehicular Networking Conference (VNC), pages 1-8.

Bill, B. (2018). Busy street scene with shoppers and commuters HD file stock footage https: //www. youtube.com/watch?v=LGLAmIfXMUc, Cars stop at traffic light Manchester uk circa 2013 stock footage - https: / / www. youtube. $\mathrm{com} / \mathrm{watch} ? \mathrm{v}=$-9Eid2BH8Mo.

Cisco (2018). Cisco visual networking index: Global mobile data traffic forecast update, 2018-2023.

Ferronato, J. J. and Trentin, M. A. S. (2015). Simulação de vanets utilizando ferramentas omnet++, sumo e veins.

Immich, R., Borges, P., Cerqueira, E., and Curado, M. (2014). Adaptive motion-aware FEC-based mechanism to ensure video transmission. In IEEE Symposium on Computers and Communication (ISCC), pages 1-6.

Immich, R., Cerqueira, E., and Curado, M. (2015). Adaptive QoE-driven video transmission over Vehicular Ad-hoc Networks. In IEEE Conference on Computer Communications Workshops (INFOCOM WKSHPS), pages 227-232.

Immich, R., Cerqueira, E., and Curado, M. (2018). Efficient high-resolution video delivery over vanets. Wireless Networks.

Noori, H. (2012). Realistic urban traffic simulation as vehicular ad-hoc network (vanet) via veins framework.

Olsson, M., Rommer, S., Mulligan, C., Sultana, S., and Frid, L. (2009). SAE and the Evolved Packet Core: Driving the mobile broadband revolution. Academic Press.

Rosário, D., Zhao, Z., Silva, C., Cerqueira, E., and Braun, T. (2013). An omnet++ framework to evaluate video transmission in mobile wireless multimedia sensor networks. 